\title{
How Neuronal Migration Contributes to the Morphogenesis of the CNS: Insights from the Zebrafish
}

\author{
Marina Mione Danila Baldessari Gianluca Deflorian Gilda Nappo \\ Cristina Santoriello \\ IFOM, FIRC Institute of Molecular Oncology, Milan, Italy
}

\section{Key Words}

Telencephalon · Mitral cells $\cdot$ Cerebellum $\cdot$ Septum • Purkinje cells · GABAergic • Glutamatergic • Eurydendroid • tbr1 $\cdot$ eomesodermin $\cdot d l x 6 a$

\begin{abstract}
We used transgenic zebrafish expressing GFP or YFP in subpopulations of neurons to study the migration, homing process and axon extension of groups of CNS neurons in different regions of the zebrafish brain. We found that extensive migration takes place at all levels of the CNS and gives rise to nuclei or cell populations with specific identities. Here, we describe 4 previously unknown or only partially characterized migratory events taking place in the zebrafish telencephalon and rhombic lip, using 3 different transgenic lines, and identify the phenotypes of the cells undertaking these migrations. The migration of a subgroup of mitral cell precursors from the dorsocaudal telencephalon to the olfactory bulb, visualized in the $\operatorname{tg}($ tbri:YFP) transgenic line, is coupled with morphogenetic transformation of the dorsal telencephalon. The $\operatorname{tg}(1.4 d l \times 5 a-6 a: G F P)$ transgenic line provides a means to analyze the migration of GABAergic interneurons from the ventral to the dorsal telencephalon, thus extending the occurrence of this migration to another vertebrate. The $\mathrm{tg}$ (Xeom:GFP) transgenic line provides the first demonstration of the dorsoventral migration of glutamatergic septal neurons, present in mammals and now described in fish,
\end{abstract}

thus reconciling the contrasting evidence of dorsal patterning genes (tbr1, eomes) expressed in a ventral cell population. Furthermore, migration studies in the $\operatorname{tg}(1.4 d 1 \times 5 a-6 a: G F P)$ and $\operatorname{tg}($ Xeom:GFP) lines help determine the origin of $2 \mathrm{im}$ portant cell populations in the fish cerebellum: projection neurons and Purkinje cells. These examples reinforce the concept that migratory events contribute to the distribution of cell types with diverse identities through the CNS and that zebrafish transgenic lines represent excellent tools to study these events.

Copyright $\odot 2008$ S. Karger AG, Basel

\section{Introduction}

The zebrafish has hardly been used as a model for studies of brain morphogenesis due to the overt differences with the mammalian system. These differences comprise the eversion process that shapes the fish telencephalon, in contrast with the evagination process that generates the telencephalic hemispheres in all other vertebrates [Nieuwenhuys et al., 1988; Tropepe and Sive, 2003; Wullimann et al., 1996], and the absence of primary motor and sensory telencephalic areas. Peculiarities in the morphogenesis, cytoarchitectonics and organization of other areas, for example the cerebellum, also contribute to the notion that the zebrafish can only be used for studies of early neurogenesis or comparative evolution.

\section{KARGER \\ Fax +4161306 1234 \\ E-Mail karger@karger.ch}

www.karger.com (c) 2008 S. Karger AG, Basel

0378-5866/08/0303-0065\$24.50/0

Accessible online at:

www.karger.com/dne
Marina Mione

IFOM, FIRC Institute of Molecular Oncology

Via Adamello, 16, IT-20139 Milan (Italy)

Tel. +390257430 3229, Fax +390257430 3231

E-Mail marina.mione@ifom-ieo-campus.it 
However, the undisputed advantages of the zebrafish model (ideal for genetic, imaging and embryological studies) have provided further incentive to study and understand the developmental neuroanatomy of this divergent vertebrate. The generation of transgenic lines that allow direct visualization of neuronal populations in live zebrafish during migration, axon extension and establishment of connections is a great resource for morphogenetic studies.

We used zebrafish transgenic lines to understand how neuronal migration contributes to the morphogenesis of the olfactory bulb (OB), telencephalon and cerebellum and to the homing process of different neuronal populations in a given area. We decided to use 2 classes of transgenic lines that mark neurons and their precursors endowed with a genetic program leading to the generation of neurons with a 'dorsal' or a 'ventral' character [Hevner et al., 2006; Wilson and Rubenstein, 2000] in the telencephalon and cerebellum, and separately. These lines are the $\operatorname{tg}(t b r 1: Y F P)$ and the $\operatorname{tg}($ Xeom:GFP) lines for the dorsal genetic program (this report) and the $\operatorname{tg}(1.4 d l \times 5 a$ $6 a: G F P)$ for the ventral genetic program [Stuhmer et al., 2002; Zerucha et al., 2000].

The OB of vertebrates forms as a paired structure at the rostral tip of the telencephalon. In the fish, as in other vertebrates, the $\mathrm{OB}$ has a laminar structure composed of 4 principal layers containing different types of neurons and glial cells [Byrd and Brunjes, 1995]. The main type of projection neuron of the $\mathrm{OB}$, the mitral cell, is among the first cell type to differentiate, it receives direct axonal innervation from the olfactory receptor neurons in the olfactory epithelium and projects to the telencephalon. When and where this cell type originates is not completely understood. In mammals a dual origin of the OB has been hypothesized, similarly to other compartments of the telencephalon including the cerebral cortex and the amigdala [Anderson et al., 1999; Puelles and Rubenstein, 2003; Sur and Rubenstein, 2005]. The dual origin of many telencephalic compartments is based on the presence of 2 main cell categories: projection neurons originating from the dorsal side of the ventricular zone and interneurons, born on the ventral side; extensive tangential migration of interneurons is then responsible for the mixing of these cell types. Indeed, projection neurons are thought to undergo almost exclusively radial migration and to remain confined to the dorsal telencephalon.

While interneurons have been visualized migrating from the anterior pallial/subpallial border to the $\mathrm{OB}$ through the rostral migratory stream [Alvarez-Buylla, 1997; Smith and Luskin, 1998; Tucker et al., 2006], very little is known on the origin and migration of mitral cell precursors. A study in rats using explant cultures [Nomura and Osumi, 2004] suggested that mitral cell progenitors originate from the rostral part of the dorsal telencephalic ventricle and migrate radially, remaining close to their birth place, while evagination of the bulb under the influence of incoming axons from the olfactory sensory epithelium [Gong and Shipley, 1995] displaces the developing bulb rostrally. The establishment of olfactory circuitries and the development of different classes of projection neurons have not been studied in a live vertebrate embryo. We took advantage of a transgenic line that we generated using regulatory sequences of the zebrafish $t b r 1$ gene to drive expression of YFP in mitral cells and olfactory sensory neurons and studied the origin and migration of mitral neurons and the formation of olfactory circuitries using time-lapse analysis in live zebrafish embryos.

Using the transgenic line $\operatorname{tg}($ Xeom:GFP), which marks cells that express the eomesodermin/tbr2 gene (here called eomes), we followed the migration of another class of telencephalic neurons, a group of glutamatergic cells of the ventral telencephalon which seem to originate from a position similar to the mitral cells, but $10 \mathrm{~h}$ later. The presence of cells expressing dorsal patterning genes in the ventralmost region of the telencephalon, in the stalk region and in the diencephalon has been documented in the diagonal band and stria terminalis of many vertebrates (mouse and chick) [Brox et al., 2004; Puelles et al., 2000]; however, information on the origin and function of these cells is lacking. In the $\operatorname{tg}($ Xeom:GFP) transgenic line these cells are seen undergoing a dorsal to ventral migration and extending axons outside of the telencephalon, thus suggesting that they may be projection neurons.

The $\operatorname{tg}(1.4 d l x 5 a-6 a: G F P)$ transgenic line was used to study the migration of telencephalic interneurons from the ventral to the dorsal telencephalon, an event that has been described in all vertebrates [reviewed by Marin and Rubenstein, 2001; Metin et al., 2006]. In our analysis, this migration seems to have similar features to those described in other species, with perhaps the only exception that it is a long-lasting event.

We used the same line to follow the migration of a subpopulation of early-born neurons in the hindbrain region starting from $24 \mathrm{~h}$ postfertilization (hpf). Given the stability of the expression of the transgene, we were able to determine the phenotype of these cells in 3-week- and 5month-old zebrafish, observing their morphology, projection and molecular phenotype. Our data suggest that the cells migrating from the upper rhombic lip (RL) be- 
tween 18 somites and 48-72 hpf may be the precursors of cerebellar projection neurons, playing similar functions to the deep cerebellar nuclei (DCN) in mammals. By contrast Purkinje cell precursors are seen originating from the cerebellar ventricular zone in the $\operatorname{tg}($ Xeom:GFP) transgenic line.

\section{Materials and Methods}

Fish Strains and Maintenance

The following transgenic lines were used in this study: $\operatorname{tg}(1.4 d l x 5 a-6 a: G F P)$ [Zerucha et al., 2000], $\operatorname{tg}(t b r 1: Y F P)$ and tg(Xeom:GFP).

Raising, spawning and maintaining of zebrafish lines were performed according to Kimmel et al. [1995] and Westerfield [1995].

\section{Time-Lapse Analysis}

All migrations were imaged with a TCS SP2 Leica confocal microscope, water immersion objectives $(20 \times$ and $40 \times)$ and a total length of time lapses between 3 and $12 \mathrm{~h}$. To determine the best stage, length and frequency of image acquisition for each migration, several trials at different stages were carried out. Zebrafish embryos of the specified age were dechorionated and lightly anesthetized with MS222 (Sigma) dissolved in embryo medium. Embryos were then oriented in a well made with a glass ring sealed on a coverslip with silicon glue in $1.5 \%$ low melting point agarose warmed to $37^{\circ} \mathrm{C}$ and cointaining MS222.

The migration of $\mathrm{OB}$ mitral neurons was studied using the $\operatorname{tg}($ tbr:YFP) transgenic line (Santoriello et al., unpublished). Time lapses were recorded at $18-36 \mathrm{hpf}$ for $10-12 \mathrm{~h}$ in a rostrocaudal ventrally tilted plane, so as to image the developing $\mathrm{OB}$, which at this stage is still located at the surface of the dorsal telencephalon.

To study the dorsal to ventral migration of the paraseptal neurons, we used the $\operatorname{tg}($ Xeom:GFP) transgenic lines (Nappo et al., unpublished). Imaging was carried out in both coronal and parasagittal planes from $24-42 \mathrm{hpf}$ for 5-12 h each. The description of the generation of the 2 unpublished transgenic lines $\operatorname{tg}(t b r: Y F P)$ and $\mathrm{tg}(\mathrm{Xeom}: \mathrm{GFP})$ will be given in separate reports.

We used the transgenic line $\operatorname{tg}(1.4 d l x 5 a-6 a: G F P)$ to image cell migration in the telencephalon and in the RL. Migration in the ventral telencephalon was imaged in the rostrocaudal plane (coronal) and at several stages, starting from $24 \mathrm{hpf}$ to 5 days postfertilization (dpf), for a minimum of $8 \mathrm{~h}$ each, and in at least 5 live specimens for each stage. We observed the largest number of migrating cells between 3 and $5 \mathrm{dpf}$, so we performed most of the analysis in that interval. Migration in the RL was studied mostly at $24 \mathrm{hpf}$ for $8-10 \mathrm{~h}$ and images were collected in the mediolateral (parasagittal) and dorsal planes.

\section{Immunohistochemistry and in situ Hybridization}

Double staining for GFP and calretinin (olfactory sensory neurons and their projections) or zebrin II (zebrin, cerebellar Purkinje cells) was performed on cryostat sections obtained from zebrafish fixed in $4 \%$ paraformaldehyde at different stages (5 dpf, 1 month postfertilization) as described [Costagli et al., 2002]. The following antisera were used: mouse monoclonal anti-GFP (Sigma, Italy), rabbit polyclonal anti-GFP (Torrey Pines, USA) and rabbit polyclonal anti-calretinin (Swant, Switzerland).

Combined in situ hybridization for tbr1 [Mione et al., 2001], vglut2.1a,b,c and vglut2.2a,b,c transporters, used together and collectively called vglut2 [Higashijima et al., 2004], glutamic acid decarboxylases (gad65/67a,b, collectively called gad [Higashijima et al., 2004]) and GFP immunohistochemistry were performed as described [Costagli et al., 2002]. Fluorescent substrate HNPP/Fast Red (Roche, Germany) was used for digoxigenin-labeled cRNA probes, following detection of GFP antibody with Alexa488 goat anti-rabbit antiserum (Molecular Probes, USA).

Bromodeoxyuridine (BrdU) uptake and labeling was performed at 3, 4 and $5 \mathrm{dpf}$ in the $\operatorname{tg}(1.4 \mathrm{dl} \times 5 a-6 a$ :GFP) line [as described in Costagli et al., 2002].

\section{Three- and Four-Dimensional Reconstruction}

We used the modules visualization and quantitation of the Volocity software (Improvision, USA) to build the 3-dimensional models shown in online supplement videos 4 and 11 and to measure the speed of migration of $\operatorname{tg}(1.4 d l \times 5 a-6 a: G F P)$ cells in the telencephalon.

\section{Cell Count in the $\operatorname{tg}(1.4 \mathrm{dl} \times 5 \mathrm{a}-6 \mathrm{a}: \mathrm{GFP})$ Line}

To count GFP-positive $(+)$ cells in the telencephalon of $\operatorname{tg}(1.4 d l x 5 a-6 a: G F P)$, we used serial cryostat sections (15 $\mu \mathrm{m}$ tick) stained with anti-GFP antiserum from 5 samples for each stage ( $3 \mathrm{dpf}, 5 \mathrm{dpf}, 15$ days and 1 month) and summed up all positive cells in the telencephalon.

\section{Results}

\section{The Migration of Mitral Cell Precursors}

The migration of mitral cell precursors can be observed in embryos of the $\operatorname{tg}(t b r 1: Y F P)$ transgenic line starting from the 18 -somite stage. Tbrl is a T-box transcription factor expressed by differentiating neurons of the dorsal telencephalon including the mitral cell precursors in the mouse [Bulfone et al., 1995; Bulfone et al., 1998] and zebrafish [Mione et al., 2001]. This transgenic line was generated using genomic sequences of the zebrafish tbrl gene [Santoriello et al., in preparation; see also Yoshida and Mishina, 2005] and faithfully reproduces most of the expression pattern of the endogenous gene (not shown).

YFP fluorescent cells in the telencephalic region of the neural tube of the $\operatorname{tg}(t b r 1: Y F P)$ transgenic line appear around $16 \mathrm{hpf}$ (before the formation of the telencephalic flexure) in 2 regions: the rostrally located ventral telencephalon and the more caudal dorsal telencephalon (fig. 1B). The latter cells are large and initially bipolar, to then become multipolar. They are seen moving from a dorsolateral position to a location just dorsal to the developing olfactory placode (online suppl. video 1, www. 
Fig. 1. Migration of mitral cells in the OB. YFP indicates that the images were taken from live $t g(t b r 1: Y F P)$ embryos. GFP indicates that a GFP antiserum was used. A Morphogenetic movements leading to the final location of the $\mathrm{OB}$ at the rostral tip of the telencephalon at different developmental stages. Black ellipse indicates a group of mitral cell precursors moving from the dorsal telencephalon to a more ventral position. B Frontal view of the telencephalon in the $\operatorname{tg}(t b r 1: Y F P)$ transgenic line at $18 \mathrm{hpf}$. YFP+ cells are present in the rostral ventral telencephalon (arrowheads) and in the caudal dorsal telencephalon (arrows). C Lateral view of a $30 \mathrm{hpf}$ embryo showing YFP sensory receptor neurons sending their axons (arrow) to the olfactory epithelium (OE, dashed circle). Arrowhead points to a group of mitral cell axons descending towards the ventral telencephalon. D YFP+ cells scattered in the OB of a 72 hpf larva. E Lateral view of the telencephalon of a dissected brain from a 4-day-old larva. GFP immunofluorescence shows tbr1-YFP cells projecting towards the dorsocaudal telencephalon through the lateral olfactory tract (LOT). Asterisk indicates a group of YFP cells in the septal region. $\mathrm{AC}=$ Anterior commissure. F, G Double immunofluorescence staining (see colors in fig. 7A) with GFP (F) and calretinin (cr) antibodies (G) reveals that dendrites of GFP+ cells make contact with cr+ sensory axons. H, I (See colors in fig. 7B) GFP cells express vglut2 (arrow in I), marker of glutaminergic projection neurons (see also fig. 7A, B). Calibration bars $=20 \mu \mathrm{m}$.
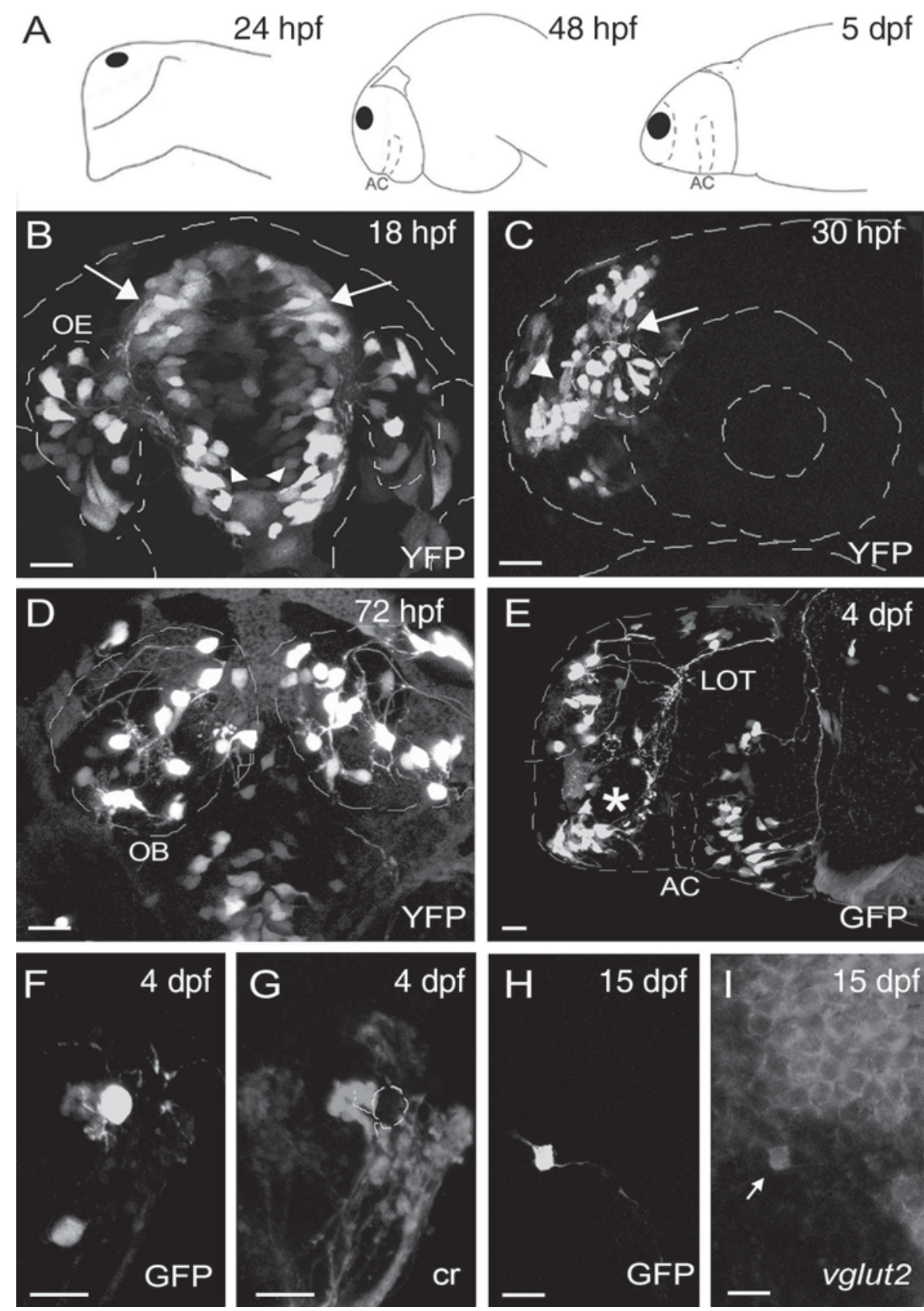

karger.com/doi/10.1159/000109853), where scattered YFP+ sensory neuron precursors (fig. 1C) send their axons. Around 30-40 mitral cell precursors disperse within this region, remaining superficial and moving rapidly to sense the environment. None of these cells is seen returning to the midline ventricular zone for division (as observed for the next 4 days), indicating that they are postmitotic. However, some of them can be observed sending their axons rapidly towards the paraseptal group of tbrl:YFP+ cells located in the ventral telencephalon from $24 \mathrm{hpf}$ onwards and for at least $12 \mathrm{~h}$ (online suppl. video 2, www.karger.com/doi/10.1159/000109853) and elaborating complex dendritic trees based on a frantic explorative behavior (starting at $42 \mathrm{hpf}$ and continuing for at least the next 3 days, fig. 1D; online suppl. video 3, www.karger.com/doi/10.1159/000109853). The final location of the bulb and all its components, including the subpopulation of tbr:YFP+ cells, presumably mitral 
neurons, at the level of the ventral telencephalon is the result of morphogenetic movements and differential growth of telencephalic compartments (see diagram in fig. 1A).

To make sure that the cells expressing YFP in the rostral telencephalon of this line represent $\mathrm{OB}$ mitral neurons, we performed double immunofluorescence with calretinin (a marker of olfactory sensory neurons and their projections) and GFP (to detect YFP-expressing cells) antisera on $4 \mathrm{dpf}$ brains. The results show the complementary labeling of mitral cells by YFP (fig. 1F, 7A) and that of the sensory axons by calretinin (fig. 1G, 7A). We also used in situ hybridization for vesicular glutamate transporters 2 (vglut2, markers of glutamatergic projection neurons, including mitral cells) followed by GFP immunohistochemistry to reveal coexpression of these markers with YFP (fig. 1H, I, 7B). The 3-dimensional reconstruction of the brain of $4 \mathrm{dpf}$ transgenic larvae reveals the projection pathway of the YFP-expressing cells in the OB. From these labeling experiments it appears that tbrl:YFP+ neurons in the OB represent a subpopulation of mitral cells, scattered throughout the $\mathrm{OB}$ and projecting towards the dorsocaudal telencephalon mainly through the lateral olfactory tract (fig. 1E; online suppl. video 4, www.karger.com/doi/10.1159/000109853).

\section{Late Migrating Neurons in the Telencephalon of tg(Xeom:GFP) Embryos}

GFP-expressing cells appear around $28 \mathrm{hpf}$ in the telencephalon of $\operatorname{tg}(\mathrm{Xeom}: \mathrm{GFP})$ transgenic embryos. This is in contrast with the expression of endogenous eomes, which in the telencephalon starts at around $11 \mathrm{hpf}$ (5-somite stage) [Mione et al., 2001] and may be due to the different regulatory elements present in the Xenopus laevis genomic sequence used to generate this line (Nappo et al., in preparation). Paired groups of GFP-expressing cells appear in the lateral region of the telencephalon (group 1 , fig. 2A-C) more or less at the level of the olfactory placode, at the telencephalic/diencephalic border (group 2, fig. $2 \mathrm{~A}-\mathrm{C}$ ) and in the midbrain tegmentum (group 3, fig. $2 \mathrm{~A}-\mathrm{C}$ ). Here we describe the migration of the telencephalic group: these cells originate from the corresponding ventricular zone, they first move towards the lateral side and then proceed rapidly towards the ventral telencephalon (online suppl. video 5, www.karger.com/doi/ 10.1159/000109853).

Most of the GFP+ cells will congregate at the level of the septal area (a few GFP+ cells migrate to the ventral $\mathrm{OB}$, arrow in fig. 2E), just rostral to the anterior commissure (fig. 2D, E). The 3 cell groups (1-3) are interconnect- ed through the anterior commissure and the middle forebrain bundle (MFB, fig. 2D, F). Indeed, in time lapses recorded from $30 \mathrm{hpf}$ onwards, group $1 \mathrm{GFP}+$ cells are seen extending axons in 2 directions: one towards the other side, as part of the anterior commissure (online suppl. video 6, www.karger.com/doi/10.1159/000109853) and the other towards group 2, i.e. to the GFP-expressing cells in the ventral diencephalon (online suppl. videos 5 and 6 , www.karger.com/doi/10.1159/000109853), contributing to the formation of the MFB. Group 2 neurons then project to another GFP+ nucleus located in the midbrain tegmentum (group 3, fig. 2B, F). Telencephalic Xeom:GFPexpressing cells probably correspond to the eomes/tbrlexpressing cells located in the ventral telencephalon of zebrafish [Mione et al., 2001] and of many other vertebrates [Brox et al., 2004; Puelles et al., 2000].

To get insights into the phenotype of the telencephalic Xeom:GFP+ cells, we analyzed them at later stages (3 weeks/2 months postfertilization) using markers for different cell types combined with GFP immunohistochemistry. At these stages, the GFP+ cells appear as large cells (15-18 $\mu \mathrm{m}$ in diameter) with multipolar somata (fig. 2GI). Of several markers used, only vglut 2 mRNAs were coexpressed with GFP (fig. 2J, K, 7C), whereas gad mRNAs were not (fig. 2L). Thus the Xeom:GFP+ cells migrating from the dorsal to the ventral telencephalon and settling in the lateral region of the septum correspond to septal glutamatergic neurons described in mammals [Manseau et al., 2005].

\section{Dorsal Migration of Ventral Neuronal Precursors in} the $\operatorname{tg}(1.4 \mathrm{dl} x 5 \mathrm{a}-6 \mathrm{a}: \mathrm{GFP})$ Transgenic Line

In all vertebrates, a subpopulation of ventral telencephalic neurons migrates to the dorsal telencephalon to provide it with inhibitory interneurons. In zebrafish this migration can be visualized in the transgenic line $\operatorname{tg}(1.4 \mathrm{dl} x 5 \mathrm{a}-6 a: G F P)$; in this line, starting from $3 \mathrm{dpf}$, an increasing number of GFP+ cells undergo a complex and prolonged ventrodorsal and rostrocaudal migration that brings $>700$ interneurons to the dorsal telencephalon. Despite the large number of neurons involved and the prolonged timing of this event, it is not easy to visualize it while it is happening for a number of technical reasons (see Discussion). By imaging $\operatorname{tg}(1.4 d l x 5 a-6 a$ :GFP) embryos at different stages and planes and for different lengths of time we observed scattered GFP+ cells undergoing rapid and unpredictable translocation from their site of origin in the ventral telencephalon to a more dorsal location. To make sure that these movements resulted in the stable translocation of cells from the ventral to the dorsal 

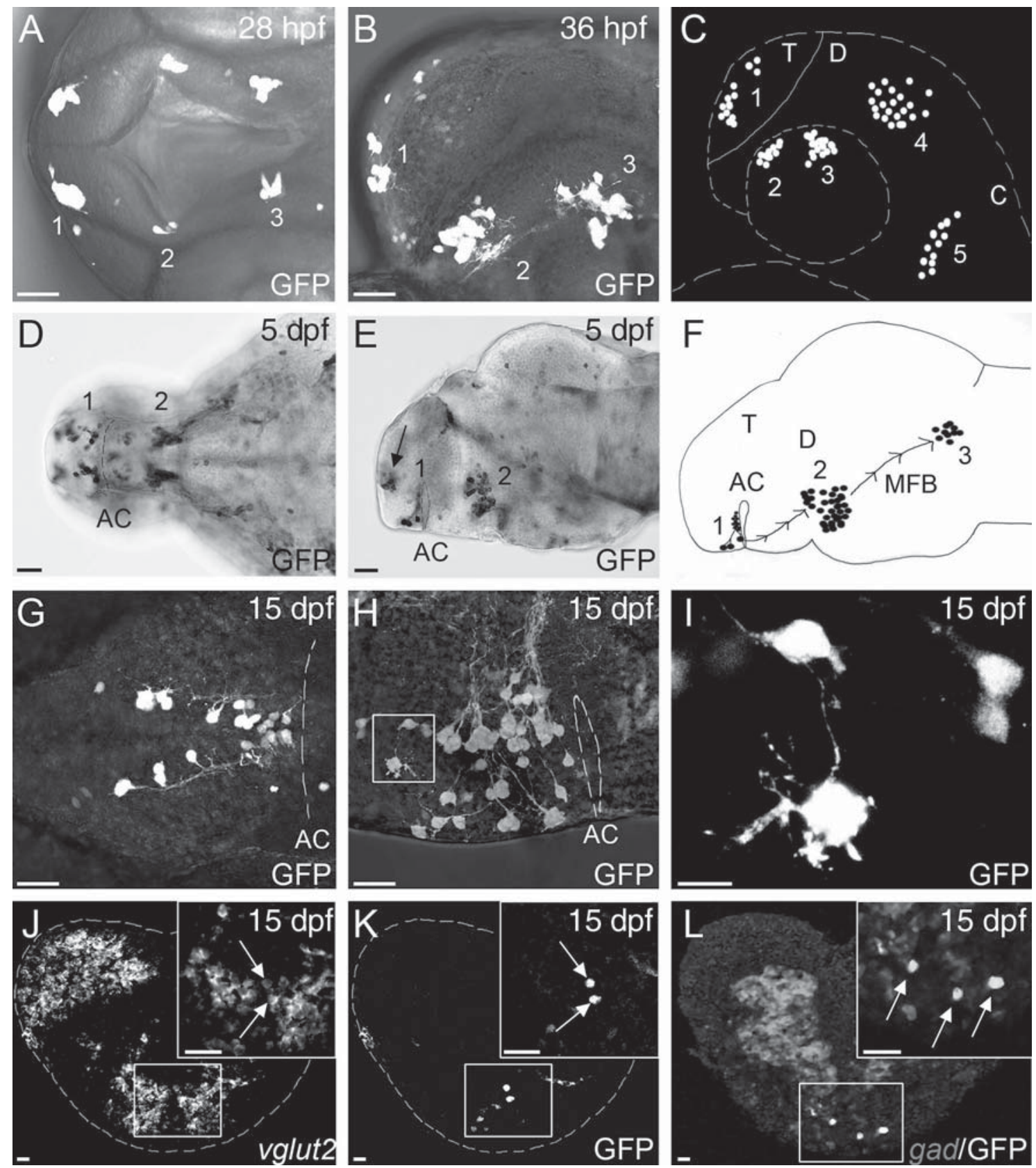

Fig. 2. GFP expression in the $t g(X e o m: G F P)$ transgenic line identifies groups of migrating cells. Staining for the markers indicated in the bottom right corner in whole mounts $(\mathbf{A}, \mathbf{B}, \mathbf{D}, \mathbf{E})$ or cryostat sections $(\mathbf{G}-\mathbf{L})$. Age is indicated in the top right corner. A Dorsal view of the forebrain of a $28 \mathrm{hpf}$ embryo, showing 3 groups of GFP+ cells, group 1 in the telencephalon, group 2 at the border between telencephalon and diencephalon, and group 3 in the midbrain tegmentum. B Lateral view of the forebrain of a $36 \mathrm{hpf}$ immunostained embryo, showing groups 1, 2 and 3. C Cartoon depicting the 5 groups of GFP+ cells present in the head of a 36 hpf embryo. D, E Dorsal (D) and lateral (E) views of $5 \mathrm{dpf}$ immunostained brain showing the location of groups 1 and 2 at this stage. $\mathbf{F}$ Cartoon illustrating groups 1,2 and 3 and their connec- tions at $5 \mathrm{dpf}$. G-I GFP+ cells in the brain of 15-day-old $\mathrm{tg}$ (Xeom: GFP) larvae; ventral view (G) and lateral view (H) of the septal region in the precommissural ventral telencephalon. I High magnification of a septal Xeom:GFP neuron (boxed in $\mathbf{H}$ ). J-L Double staining (see colors in fig. 7C). GFP+ cells (K) in the septum of a $15 \mathrm{dpf}$ transgenic embryo processed for vglut2 in situ hybridization (J) or gad in situ hybridization (L). Insets show GFP-expressing cells at higher magnification, $\mathbf{J}$ and $\mathbf{K}$ are confocal images of the same section acquired with different laser combinations (see fig. 7C). L shows both gad in situ hybridization (grey signal) and GFP immunostaining (white cells). In A-I rostral is to the left and dorsal to the top. $\mathrm{AC}=$ Anterior commissure; $\mathrm{T}=$ telencephalon; $\mathrm{D}=$ diencephalon; $\mathrm{C}=$ cerebellum. Calibration bars: $20 \mu \mathrm{m}$. 
telencephalon, we evaluated the number of GFP+ neurons in the dorsal telencephalon at different times (see table 1). The number increased from 1 cell at $3 \mathrm{dpf}$ to around 700 cells at 1 month.

At $5 \mathrm{dpf}$ scattered GFP+ cells were seen in the dorsal telencephalon (fig. 3A, B). At 1 month the morphology of the GFP+ cells is well developed (fig. 3A, inset) and resembles that of dorsal telencephalic interneurons detected by other authors with GAD immunohistochemistry [Castro et al., 2006a].

We also evaluated whether migrating cells undergo cell division by exposing the embryos to BrdU for $48 \mathrm{~h}$ between 3 and $5 \mathrm{dpf}$. We did not find double (GFP/BrdU) labeled cells in the dorsal telencephalon (data not shown), indicating that most of the GFP+ cells found in the dorsal telencephalon of $\operatorname{tg}(1.4 d l x 5 a-6 a: G F P)$ zebrafish had migrated there as individuals, rather than being generated by local proliferation.

To document this migration, we imaged several $3 \mathrm{dpf}$ (online suppl. video 8, www.karger.com/doi/10.1159/ 000109853) and $5 \mathrm{dpf} \operatorname{tg}(1.4 d l \times 5 a-6 a: G F P)$ embryos in a frontal plane for $>12 \mathrm{~h}$ (fig. 3C, online suppl. video 9, www.karger.com/doi/10.1159/000109853). Analysis of these time lapses at different planes of focus (cells were colored according to depth, online suppl. video 10, www. karger.com/doi/10.1159/000109853) allowed us to detect few cells (1-8 at the most for each time lapse) undergoing migration. Unlike all the other migrations described here, the trajectory of the $\operatorname{tg}(1.4 d l x 5 a-6 a: G F P)$ migrating cells is very convoluted and hard to predict (see diagram in fig. 3C). Examples of the complicated migratory behaviors of these cells are given in the time-lapse movies, in figure $3 \mathrm{C}$ and in the diagram (see fig. 3C) reconstructing the trajectory of one of the migrating cells.

Migrating cells undergo cycles of rapid movements followed by standstills, accompanied by exploratory behavior of their neurites. Looking at the moving cells from a frontal view in 2-dimensional projections of the time points, the direction of cell movements seems random. However, when using a program that allows 4-dimensional reconstruction (visualization module, Volocity), we can appreciate that most of the migrating cells imaged between 3 and $5 \mathrm{dpf}$ first undergo a movement of vertical translation (from ventral to dorsal) followed by rostrocaudal migration (online suppl. video 11, www.karger. com/doi/10.1159/000109853). Using a cell tracking program (quantitation module, Volocity), we established that the speed of the migrating cells is variable (from 1 to $6 \mu \mathrm{m} / \mathrm{h}$ ), the direction is rostrocaudal for most of them, they all move by translocating their soma towards their
Table 1. Number of GFP+ neurons in the dorsal telencephalon of $\operatorname{tg}(1.4 d l x 5 a-d l x 6 a: G F P)$ zebrafish

\begin{tabular}{rc}
\hline Stage & Number of cells \pm standard deviation \\
\hline $3 \mathrm{dpf}$ & $5 \pm 1$ \\
$5 \mathrm{dpf}$ & $16 \pm 5$ \\
$14 \mathrm{dpf}$ & $122 \pm 31$ \\
$30 \mathrm{dpf}$ & $765 \pm 110$ \\
\hline
\end{tabular}

leading process, and they have a classical bipolar shape while moving but become ameboid during the static cycles in which they extend exploratory neurites. No cell divisions were observed during migration according to the fact that BrdU uptake was never detected in GFP+ migrating cells, between 3 and $5 \mathrm{dpf}$.

To identify the phenotype of the migrating cells, we stained them for expression of the GABA-synthesizing enzymes gad65 and gad67a,b using fluorescent in situ hybridization combined with GFP immunohistochemistry. All GFP+ cells in the dorsal telencephalon of $5 \mathrm{dpf}$ (fig. 3D, E, 7D) and 5-month-old zebrafish (fig. 3F, G, 7E) expressed gad65/67a,b mRNAs, although not all gad-expressing cells were GFP+. Thus, the dlx5a-6a:GFP+ migrating cells are the precursors of the GABAergic neurons of the dorsal zebrafish telencephalon.

\section{Migration of Cerebellar Neuron Precursors in the} $\operatorname{tg}(1.4 \mathrm{dlx} 5 \mathrm{a}-6 \mathrm{a})$ and $\operatorname{tg}(\mathrm{Xeom}: \mathrm{GFP})$ Transgenic Lines

Several studies investigating the origin of cerebellar neurons have documented the migration of neuronal precursors in the RL in zebrafish [Koster and Fraser, 2001], chick [Gilthorpe et al., 2002] and mouse [reviewed in Wingate, 2005]. The phenotypes of the migrating cells imaged in the studies in zebrafish are largely unknown [Koster and Fraser, 2001]. We noticed a prominent dorsoventral migration of large cells in the mid-hindbrain/upper RL region in the $\operatorname{tg}(1.4 d l x 5 a-6 a: G F P)$ line starting from $20 \mathrm{hpf}$. This migration occurs earlier than the migrations reported previously in the zebrafish RL [Koster and Fraser, 2001, 2006]; moreover shape and size, mode of migration and final differentiation of the migrating cells suggest that the cells reported here may be different or have a different fate from those previously described.

GFP expression in the dorsal hindbrain region of $\operatorname{tg}(1.4 d l x 5 a-6 a: G F P)$ embryos starts at around $20 \mathrm{hpf}$. We looked at the expression of the $2 d l x$ genes, $d l x 5 a$ and $d l x 6 a$, which are under the control of the enhancer used to generate this line, to check whether GFP expression in the RL represented ectopic expression, since it was never 
Fig. 3. Dorsolateral migration of ventral neurons in the $\operatorname{tg}(1.4 d l x 5 a-d l x 6 a: G F P)$ transgenic line. Staining for the markers indicated in the bottom right corner in whole mounts (A, B) or cryostat sections (D-G). Age is indicated in the top right corner. A, B Sagittal and frontal sections of $5 \mathrm{dpf}$ dissected brains immunostained with anti-GFP antibody. Few GFP+ cells have migrated into the dorsal telencephalon (arrowhead). Arrow in A points to a $\mathrm{GFP}+$ cell in the OB. At 1 month postfertilization (mpf) the morphology of GFP+ cells (A, inset) resembles that of dorsal telencephalic interneurons in other species. In $\mathbf{A}$ vertical lines indicate the region of the telencephalon subjected to confocal timelapse analysis, through coronal optical sectioning. C Snapshots covering $224 \mathrm{~min}$ of a movie recorded in a 3-day-old living embryo. One cell (arrow) migrates from a ventral (v) and medial (m) position to a more dorsal (d) and lateral (l) one. D-G gads (gad65, gad67a and gad67b) expression revealed by in situ hybridization colocalizes with GFP immunostaining in some scattered neurons (arrows). Arrowhead points to $\mathrm{gad}+$ interneuron not expressing GFP (see colors in fig. 7D). Coronal view of cryostat sections from a $5 \mathrm{dpf}$ embryo (D, E) or from a 5-month-old (5 mpf) fish (F, G). Insets in $\mathbf{F}$ and $\mathbf{G}$ show lower magnification views of double stained ( $\mathrm{gad} / \mathrm{GFP})$ sections through the telencephalon viewed with different laser settings. Calibration bars: $20 \mu \mathrm{m}$.
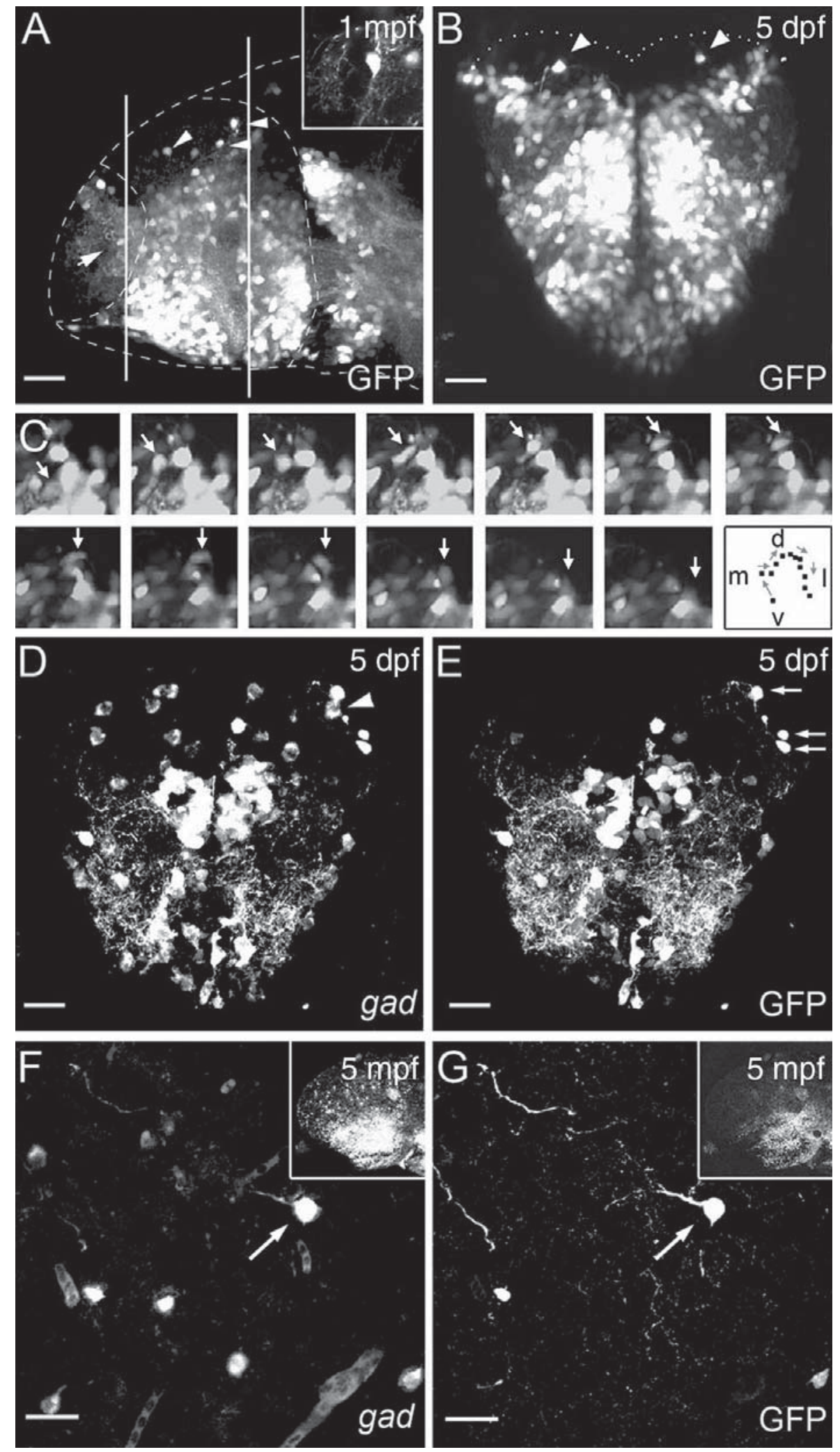
Fig. 4. Characterization of the cerebellar GFP expression in the $\operatorname{tg}(1.4 d l \times 5 a-d l x 6 a$ : GFP) transgenic line. Staining for the markers indicated in the bottom right corner in whole mounts. Age is indicated in the top right corner. A, B In the hindbrain region, the expression pattern of GFP in the transgenic line $(\mathbf{A})$ is similar to the expression of $d l x 6 a$ mRNA (B), as shown in lateral views of $30 \mathrm{hpf}$ embryos (anterior is on the left). C, D Lateral (C) and dorsal (D) views of GFP+ cells in the upper RL. E, F GFP expression identifies 3 groups of cells in the cerebellar region of $5 \mathrm{dpf}$ transgenic zebrafish. The lateral group (L) is located in the granular eminence, the medial group $(\mathrm{M})$ in the caudal lobe and the most anterior group (A) in the corpus cerebelli, as shown in lateral (E) and dorsal (F) views of the head of 5-day-old larvae (anterior is on the left). MHB = Midbrainhindbrain boundary. Calibration bars: 20 $\mu \mathrm{m}$.
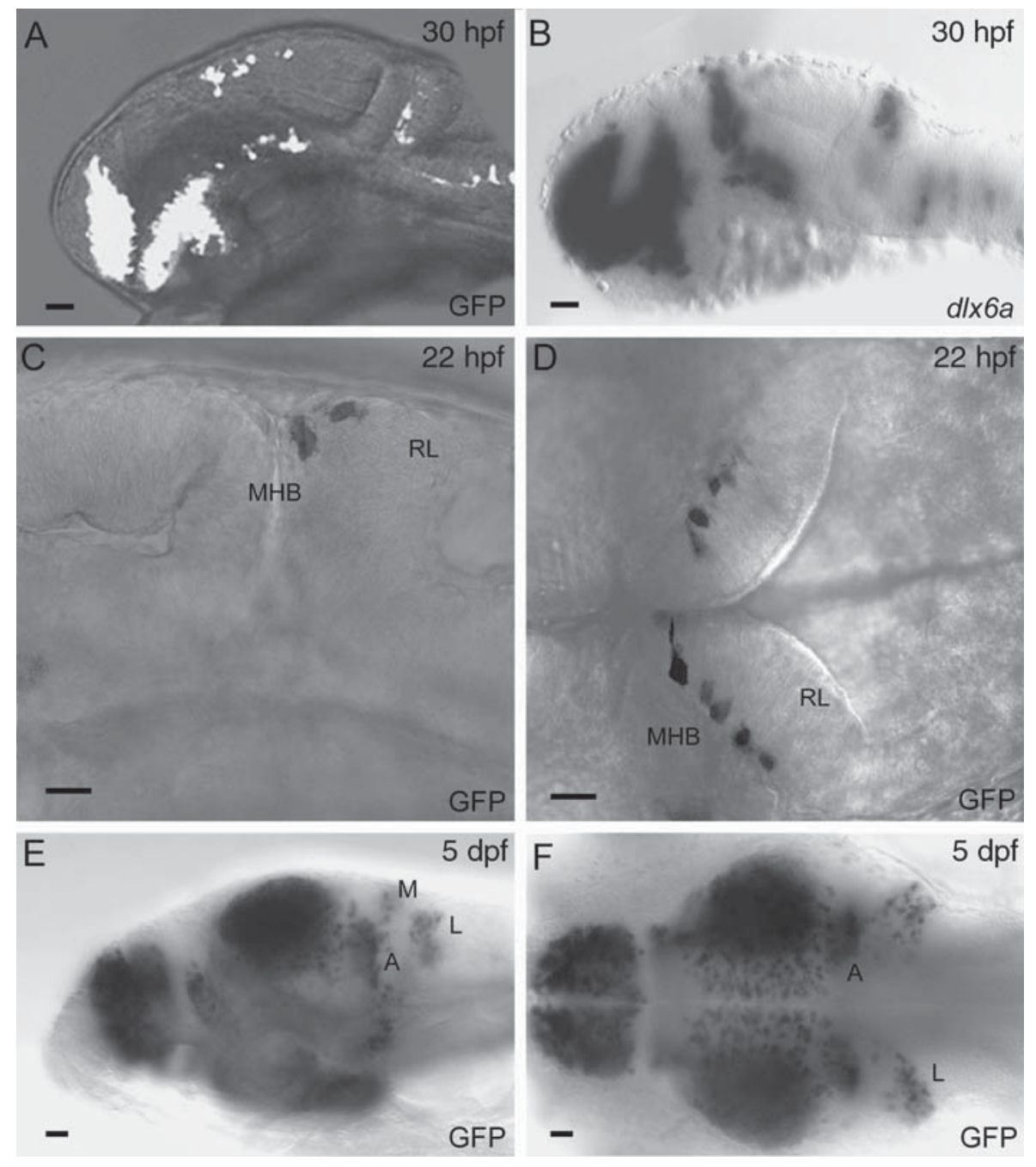

reported for a $d l x$ gene. We found that $d l x 6 a$ is expressed in the developing hindbrain region (fig. 4B), with a pattern identical to the GFP expression in the transgenic line (fig. 4A), thus suggesting that the GFP expression in the line recapitulates the expression pattern of the endogenous gene. We took images of the migrating cells both in the lateral and dorsal view, starting from $20 \mathrm{hpf}$ for $12 \mathrm{~h}$. Large $(>20 \mu \mathrm{m})$, bipolar GFP+ cells were seen migrating rapidly from the dorsal to the ventral side of the RL (see fig. $4 \mathrm{C}$ and online suppl. video 12, www.karger.com/doi/ $10.1159 / 000109853)$. In dorsal view time lapses, we observed that GFP+ precursors divide next to the upper RL border and then move towards the mid-hindbrain boundary, where they rapidly initiate a dorsoventral migration (online suppl. video 13, www.karger.com/doi/10.1159/ 000109853). The migration behavior of these cells consists in exploration with their processes followed by rapid ventral progression; like the migrations described previously [Koster and Fraser, 2001], these cells rely on their leading process for somal translocation. No more GFP+ cells are seen migrating along the RL after $52 \mathrm{hpf}$.

We then looked at the phenotype of the migrated cells in the developing and adult cerebellum. The GFP+ cells are found in 3 groups or areas in the cerebellar region of $5 \mathrm{dpf}$ zebrafish larvae (fig. 4E, F), which correspond to the granular eminence for the most lateral group (group $\mathrm{L}$ in fig. $4 \mathrm{E}, \mathrm{F}$ ), to the caudal lobe for the medial group (group $\mathrm{M}$ in fig. 4E, F) and to the corpus cerebelli (group $\mathrm{A}$ in fig. $4 \mathrm{E}, \mathrm{F}$ ) in the most anterior group. To identify the phenotype of the $\operatorname{tg}(1.4 d l \times 5 a-6 a: G F P)$, cells we studied their morphology and their molecular traits using a panel of markers at $15 \mathrm{dpf}$ and in adult fish. GFP+ cells are intermingled with Purkinje cells (revealed with anti-zebrin II antiserum) and are largely negative for this mark- 

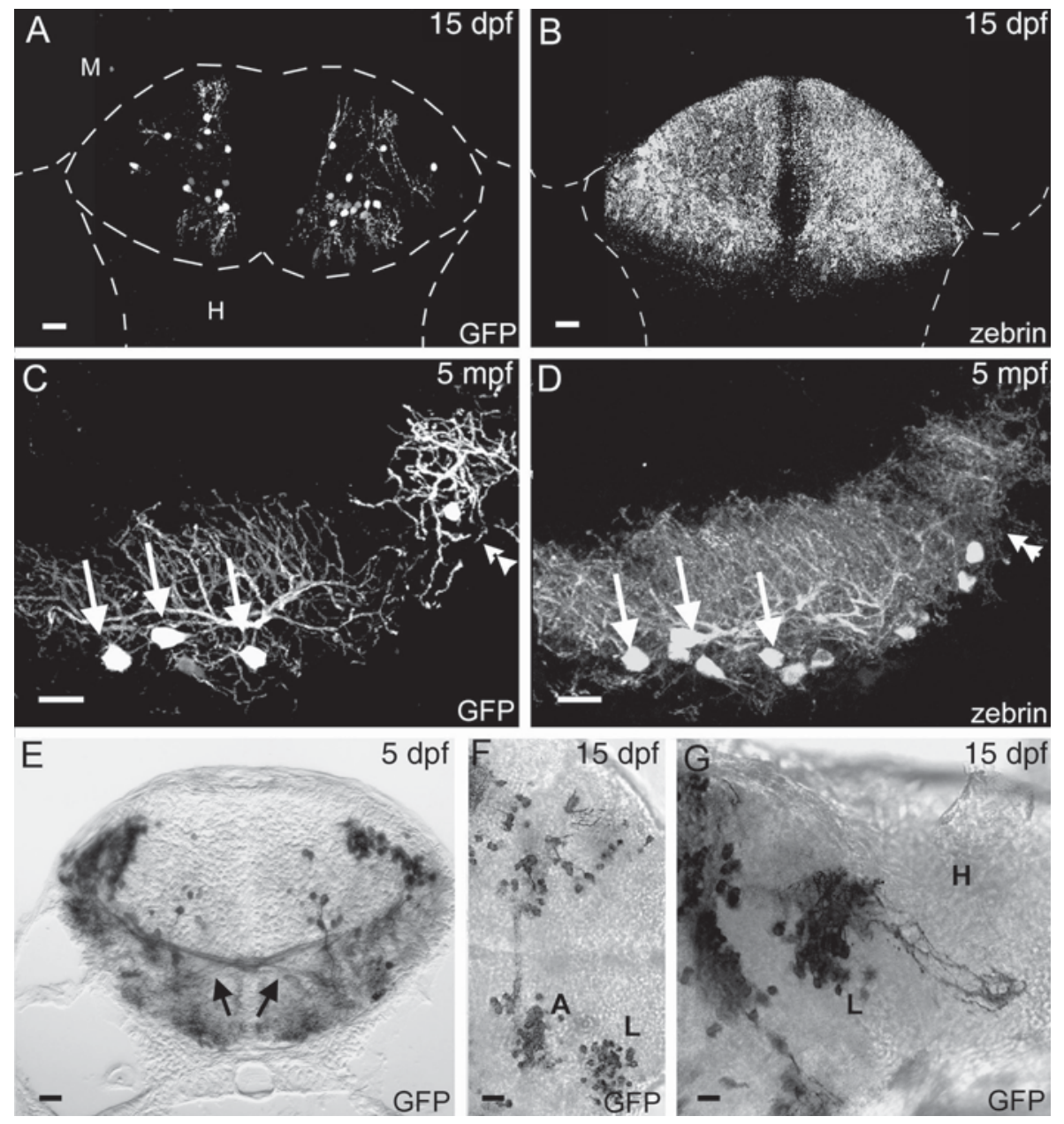

Fig. 5. Phenotype of the GFP+ cells in the cerebellum of the $\operatorname{tg}(1.4 d l x 5 a-d l x 6 a: G F P)$ transgenic line. Staining for the markers indicated in the bottom right corner in whole mounts $(\mathbf{A}, \mathbf{B}, \mathbf{F}, \mathbf{G})$ or cryostat sections (C-E). Age is indicated in the top right corner. A-D GFP-expressing cells in the cerebellum of 15-day-old transgenic larvae. A, B Dorsal views, rostral is on the top. A GFP expression in a few sparsely distributed cells. B Purkinje cells revealed with anti-zebrin II antiserum (zebrin). C, D High magnifications of sections from the cerebellum of a 5-month-old transgenic zebrafish, stained for GFP (C) and zebrin II (D). Only a few GFP+ cells are stained with a zebrin II antiserum (arrows in C and D). Double arrowhead points to a cell expressing GFP only $(\mathbf{C}, \mathbf{D})$,

er at $15 \mathrm{dpf}$ (fig. 5A, B and 7F) and at 5 months (fig. 5C, $D, 7 G)$. Dlx5a-6a:GFP+ cells in the fish cerebellum are also negative for vglut2 mRNA, whereas they express gad (fig. $7 \mathrm{H}$ ), thus revealing that they use GABA as neurotransmitter.

Some GFP+ cells are seen projecting their axons outside of the cerebellum: in the corpus cerebelli GFP+ neurons project contralaterally to nuclei in the ventral hind- whereas the majority of the cells in these locations express only zebrin II. E Transversal (cross)section of the head of a $5 \mathrm{dpf}$ transgenic larva showing GFP+ cells in the cerebellar region projecting their axons contralaterally (arrows) to nuclei in the ventral hindbrain. F Dorsal view of the cerebellar region of a 15-day-old transgenic larva showing GFP+ cells projecting their axons in the cerebellar commissure (anterior is to the left). G Lateral view of the cerebellar region of a 15-day-old transgenic larva (anterior is to the left) showing GFP+ cells of the lateral group projecting their axons to a nucleus in the caudal hindbrain. $\mathrm{A}=$ Anterior group; $\mathrm{L}=$ lateral group; $\mathrm{H}=$ hindbrain. Scale bars: $20 \mu \mathrm{m}$.

brain (fig. 5E) and to the other side in the cerebellar commissure (fig. 5F); GFP+ cells in the granular eminence (lateral group, L) send ipsilateral projections to a nucleus in the caudal hindbrain (fig. 5G).

A different population of cerebellar neurons can be visualized in the $\operatorname{tg}($ Xeom:GFP) transgenic line. Faint $\mathrm{GFP}+$ cells are firstly seen in a deep location of the rhombomere 1 region at around $30 \mathrm{hpf}$ (fig. 6A). Detailed anal- 

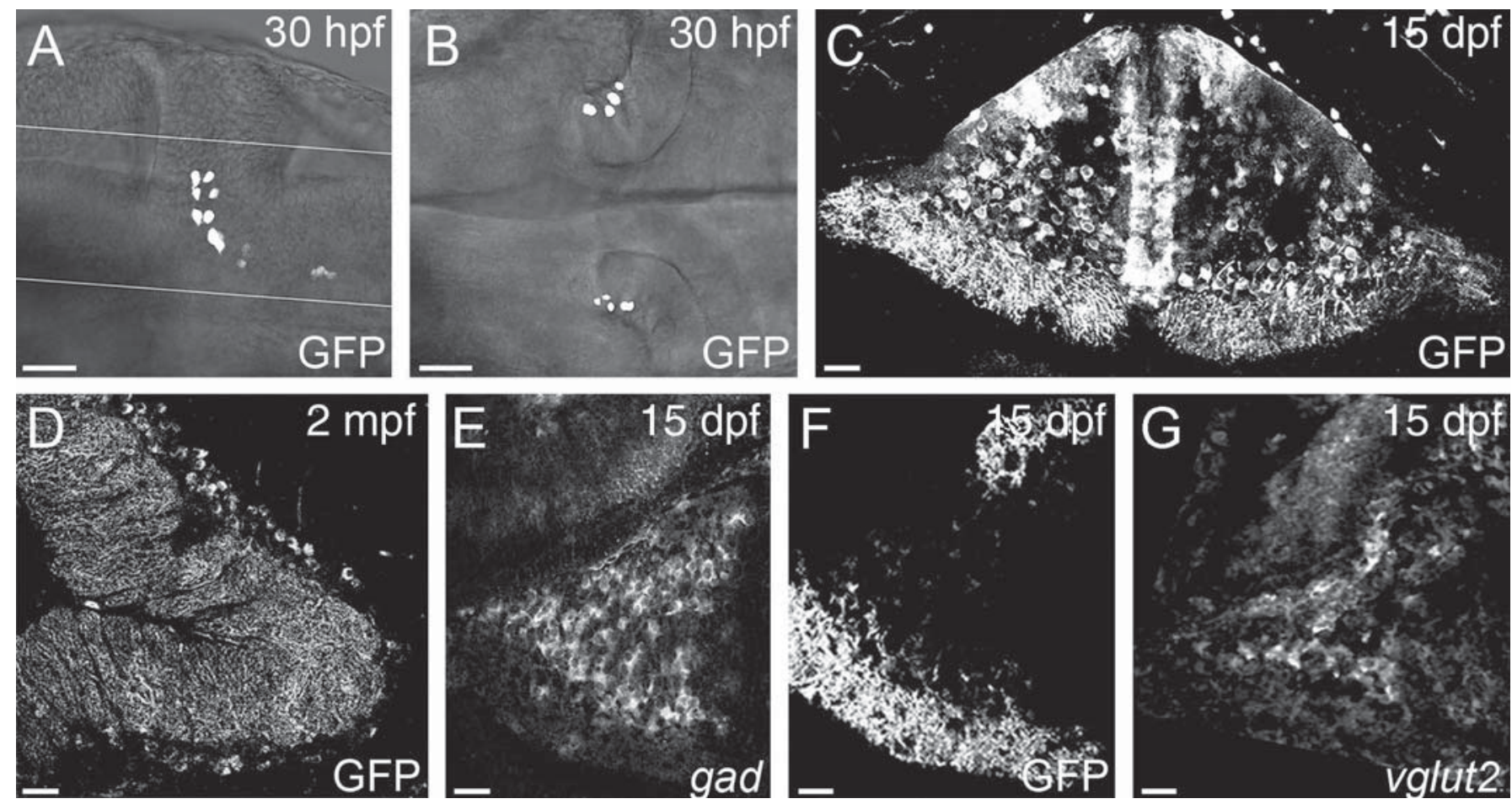

Fig. 6. Characterization of the expression of GFP in the cerebellum of the $\operatorname{tg}($ Xeom:GFP) transgenic line. Staining for the markers indicated in the bottom right corner in whole mounts $(\mathbf{A}-\mathbf{C})$ or cryostat sections (D-G). Age is indicated in the top right corner. A, B 30 hpf GFP immunostained embryos: lateral view (A) showing GFP+ cells in rhombomere 1 region; GFP+ cells are located on the rostral side of the ventricular zone of the IV ventricle (B); lines in $\mathbf{A}$ indicate the extension of the confocal stacks shown in $\mathbf{B}$.

C Immunofluorescence on a cerebellar section of a $15 \mathrm{dpf}$ brain, showing the distribution of GFP+ cells throughout the cerebellum. D GFP immunofluorescence on a cerebellar section of a 2 mpf brain showing the classical distribution of Purkinje cells. E-G GFP+ cells and mRNA transcripts in 15 dpf brain sections, views showing half cerebelli; gad in situ hybridization (E); $\mathrm{GFP}+$ cells (F); vglut2 in situ hybridization (G). Calibration bars: $20 \mu \mathrm{m}$.

ysis of their location established that these cells appear in the rostral side of the ventricular zone of the IV ventricle (fig. 6A, B). In the course of the following hours these cells increase in number but move very little from their location (not shown). At $15 \mathrm{dpf}$ these cells have spread throughout the corpus cerebelli and are characterized by the expression of the Purkinje cell marker zebrin II (fig. 6C, 7I). At 2 months, GFP+ cells have the classical morphology and distribution of Purkinje cells (fig. 6D). Moreover they express gad mRNAs (fig. 6E, 7J) but not vglut2 mRNAs (fig. 6F).

\section{Discussion}

The analysis of neuronal migration in zebrafish transgenic lines expressing fluorescent markers in subpopulations of neurons provides a degree of resolution that is unparalleled by other methods. A wealth of information can be obtained by recording neuronal cells moving in their original environment. Using this and other approaches, it is becoming clear that cell groups and individual neurons are endowed with a genetic program that coordinates all aspects of migration (start/end point, route, behavior, and so on) with molecular differentiation and axon growth. The zebrafish transgenic lines used here have provided novel information on the origin and migration of subpopulations of neurons and represent invaluable tools for the analysis of their connections and the genetic and molecular programs that regulate their behavior.

\section{The Migration of Mitral Cell Precursors Takes Place in the Context of Telencephalic Morphogenetic}

Movements

The origin of the $\mathrm{OB}$ projection neurons, the mitral cells, was elucidated by time-lapse recording of cell migration in the $\operatorname{tg}(t b r 1: Y F P)$ transgenic line. Tbrl is expressed in the mitral cells of different vertebrates ranging 

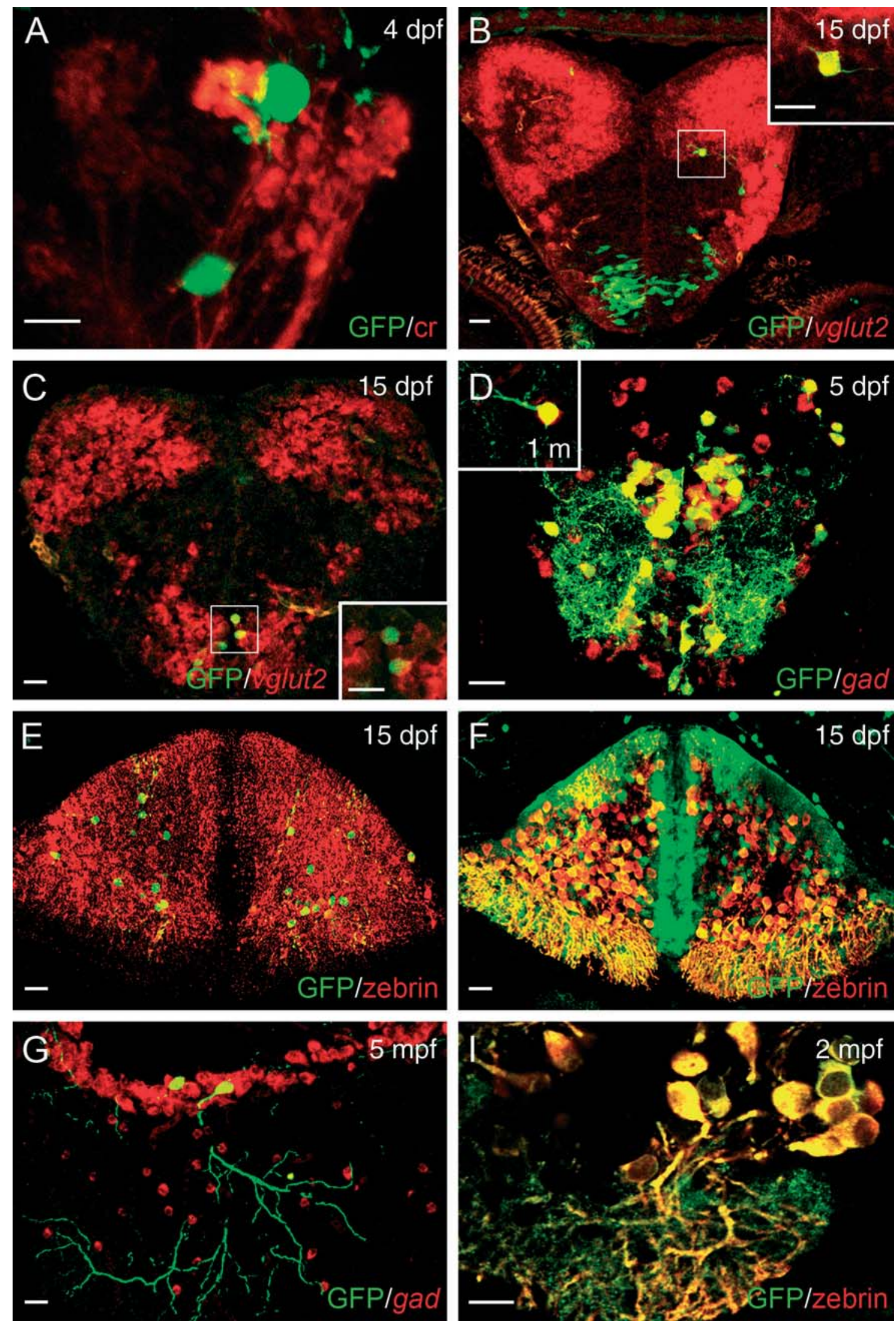
from fish to humans [Bulfone et al., 1995; Mione et al., 2001; Puelles et al., 2000] and knockout of the Tbrl gene in mouse results in the ablation of this cell type [Bulfone et al., 1998]. This suggests that this transcription factor is part of the core genetic program leading to the differentiation of mitral neurons in vertebrates. In mouse and in zebrafish all mitral cells express $t b r 1$ for a prolonged period. By contrast, YFP expression in the line that we generated using $10 \mathrm{~kb}$ of genomic sequence upstream of the start codon is transient and possibly confined to a subpopulation of mitral cells (Santoriello et al., unpublished observation). Nevertheless, mitral cell precursors express YFP robustly, thus allowing us to follow their migration and connections during the first $4 \mathrm{dpf}$. Despite the final ventral location of the $\mathrm{OB}$ in many vertebrates, the mitral neurons which sit at the center of the olfactory sensory circuitries are generated in the dorsal telencephalon, and this is well evidenced in the $\operatorname{tg}(t b r 1: Y F P)$ embryos (present work). Expression of the transgene starts simultaneously in a few olfactory sensory neurons in the olfactory epithelium and in the mitral cell precursors. This is before the outgrowth of sensory axons towards the telencephalon, as documented in our time-lapse analysis, thus suggesting that incoming sensory axons are not causative of the generation of the mitral cells. Nevertheless, mitral cell precursors are generated at the same dorsoventral level of the olfactory sensory neurons, thus suggesting

Fig. 7. Phenotype of the YFP/GFP cells in the transgenic lines. A, B $\operatorname{tg}(\operatorname{tbr} 1: Y F P)$ line. C, F, I $\operatorname{tg}(X e o m: G F P) \operatorname{line}$. D, E, G $\operatorname{tg}(1.4 d l x 5 a-$ $6 a: G F P)$ line. Double staining for the markers indicated in the bottom right corner in whole mounts $(\mathbf{A})$ or cryostat sections (B-I). Age is indicated in the top right corner. (A) Mitral cells $(\mathrm{GFP}+)$ makes contact with calretinin sensory axons in the $\mathrm{OB}$ of a $4 \mathrm{dpf} \operatorname{tg}($ tbrl:YFP) zebrafish larva. B GFP+ cells in the OB of a 15-day-old $\operatorname{tg}(t b r 1: Y F P)$ zebrafish express vglut2 genes, double immunofluoresce/in situ hybridization. C Septal GFP+ cells in the tg(Xeom:GFP) transgenic line express vglut2 genes. Cytoplasmic vglut2 transcripts in GFP+ cells visible in the inset. D Coexpression (yellow) of GFP and gad transcripts in many GFP+ cells migrated to the dorsal telencephalon in the $\operatorname{tg}(1.4 d l x 5 a-6 a$ :GFP) line at 5 days and 1 month (inset). E Double immunofluorescence for GFP and zebrin II in the cerebellum of a 15-day-old $\operatorname{tg}(1.4 \mathrm{dl} \times 5 a$ $6 a: G F P)$ larva, showing a few cells expressing both markers. F double immunofluorescence for GFP and zebrin II in the cerebellum of a 15-day-old $\operatorname{tg}$ (Xeom:GFP) larva showing that many GFP+ cells express zebrin II. G GFP+ cells in the Purkinje cell layer of a 5-month-old $\operatorname{tg}(1.4 d l x 5 a-6 a$ :GFP) zebrafish do not express gad transcripts. I All GFP+ cells in the cerebellum of a 2month-old $\operatorname{tg}($ Xeom:GFP) zebrafish express zebrin II. Calibration bars $=20 \mu \mathrm{m}$.

Migration and Morphogenesis in the Zebrafish CNS that signals inducing the development of the whole olfactory system act at a precise dorsoventral level on both neuroepithelium and olfactory placode [for review, see Brunjes and Greer, 2003]. Mitral cell precursors move very little from their initial position when compared with adjacent telencephalic neurons, thus indicating that their dorsal to ventral translocation needs to be interpreted as part of the morphogenetic movements of the OB. The mitral neuron precursors spend most of their time building elaborate dendritic trees in connection with the incoming sensory axons and projecting towards a group of smaller neurons (actively migrating from dorsal to ventral positions, see online suppl. video 2, www.karger.com/doi/10.1159/ 000109853) that end up in the ventral telencephalon (asterisk in fig. 1E). With time, due to differential growth of the dorsal versus ventral telencephalon, the mitral cell precursors become displaced anteriorly, at increasing distance from the dorsal border with the diencephalon, where they were originally located (see diagram in fig. 1A). Thus, the observation of the tbrl:YFP+ cells in our transgenic line suggests that mitral cell precursors are passively transduced rostrally and ventrally, presumably by overgrowth of the dorsocaudal telencephalon behind them. This observation lends support to the hypothesis that morphogenetic movements, rather than individual cell migration, is eventually responsible for positioning the $\mathrm{OB}$ of vertebrates in front of the brain.

The tbrl:YFP+ cells display an active local exploratory behavior from $48 \mathrm{hpf}$ onwards: it may be connected with the need to 'pair' with the correct sensory glomerulus. Indeed, it has been shown that zebrafish mitral neurons innervate a single glomerulus [Fuller et al., 2006]. Many tbrl:YFP+ mitral cell precursors initially project towards the YFP+ cells in the ventral telencephalic septum, however, by $4 \mathrm{dpf}$ they mostly project towards the caudal telencephalon (see online suppl. video 4, www.karger.com/ doi/10.1159/000109853). It appears that the projection to the septal cell group is transient and is progressively retracted while septal axons grow in the opposite direction. By $4 \mathrm{dpf}$ the majority of tbr1:YFP+ mitral cells project to the caudal telencephalon (future posterior nucleus of the dorsal telencephalon [Wullimann, 1996]) through the lateral olfactory tract.

The fact that the majority of tbr1:YFP neurons use the lateral olfactory tract to project to dorsal telencephalon suggests that this subpopulation of mitral neurons is involved mainly in conveying food-related odorants [Hamdani et al., 2001], as pheromones and sex-related odors are mainly conveyed by the middle olfactory tract (MOT) [Stacey and Kyle, 1983]. 


\section{Late Migrating Neurons in the Telencephalon of} $\operatorname{tg}$ (Xeom:GFP) Embryos

The analysis of cell migration in the $\operatorname{tg}($ Xeom:GFP) transgenic line shed light on the origin of a cell group located in the ventral telencephalon but expressing dorsal'type' genes. In mouse, chick and Xenopus expression of Tbrl has been documented in discrete nuclei of the ventral telencephalon; specifically the nuclei of the lateral, medial and accessory olfactory tract and those of the diagonal band [Puelles et al., 2000]. These cell groups are in continuation with diencephalic ventral structures (the anterior entopeduncular area and the eminentia thala$\mathrm{mi}$ ), which also express tbr1. Although only partially shown for Xenopus [Brox et al., 2004], the same nuclei also express eomes/tbr2. In zebrafish a study of eomes and tbrl expression demonstrated a similar pattern of distribution for the 2 transcripts in the ventral forebrain region [Mione et al., 2001]. In previous work we noticed the distribution of tbrl/eomes + cell groups along the MOT and the MFB, and here we observed a similar distribution for the Xeom:GFP+ cells (see fig. 2D, F, G). The observation that these cells originate from a dorsal telencephalic position and undergo an extensive migration towards the ventral telencephalon and diencephalon, accompanying the growth of the MOT and MFB, suggests that they may play pioneer roles on the formation of these major axon tracts. In the mouse tbrl+ cells are strategically located in the eminentia thalami [Puelles et al., 2000] at the border between the thalamus and the internal capsule, where they may regulate the formation of thalamocortical connections. Indeed, tbr1 knockout mice are characterized by severe defects of thalamo-cortical connections [Hevner et al., 2001; Miyashita-Lin et al., 1999]. We think that group 2 Xeom:GFP+ cells located at the ventral border between telencephalon and diencephalon at $28 \mathrm{hpf}$ correspond to the eminentia thalami cells of amniotes. Group 1 Xeom:GFP cells become distributed in 2 locations: just ventral to the $\mathrm{OB}$ at the beginning of the MOT (arrow in fig. 2E) and along the same tract in front of the AC (fig. 2G), where they project. The pioneering function on axon tract formation of dorsally derived neurons may be relevant only to developmental functions. In the mature brain of mammals glutamatergic septal neurons are core components of an important neural circuit, which is composed of regulatory (GABAergic and cholinergic [Manns et al., 2001] as well as of projection (glutamatergic) neurons [Manseau et al., 2005]. These cells project to the septohyippocampal tract and may play a key role in rhythm generation and memory formation [SanchezVives and McCormick, 2000]. Thus, we believe that we have identified a population of septal glutamatergic neurons that originate in the dorsal telencephalon and undergo extensive migration in the ventral brain regions of the zebrafish.

Dorsal Migration of Ventral Neuronal Precursors in the $\operatorname{tg}(1.4 \mathrm{dlx} 5 \mathrm{a}-6 \mathrm{a}: \mathrm{GFP})$ Transgenic Line

Since the first reports of tangential migration of GABAergic interneurons from the ventral to the dorsal telencephalon in mammals [Anderson et al., 1997; Tamamaki et al., 1997] many studies have extended this observation to other species [Cobos et al., 2001] and to diencephalic regions [Letinic and Rakic, 2001]. A number of genetic programs regulate both the migrating behavior and differentiation of GABAergic interneuron subtypes [see Marin and Rubenstein, 2001 for review], the response to environmental cues [Denaxa et al., 2001; Flames et al., 2004; Marin et al., 2003; Marin and Rubenstein, 2001], and the pathways and mode of migration of interneurons [Nadarajah et al., 2003]. It is not surprising to observe the same phenomenon in zebrafish, and the transgenic line $\operatorname{tg}(1.4 d l x 5 a-6 a: G F P)$ is well suited for these studies due to the well-known involvement of $d l x$ genes in the differentiation/migration program of the ventral-born cortical interneurons [Anderson et al., 1997]. However, migration of GFP-expressing cells from ventral to dorsal telencephalon was difficult to visualize in the line for several reasons: (a) cells migrate through a densely populated GFP+ area, sometimes including the whole extent of the ventral telencephalon, as they often start from very ventral positions; (b) cells migrate as individuals and the starting point, timing, direction and duration of their migration are unpredictable, and (c) although the final number of migrating cells is remarkable, the fact that this event is ongoing for longer than 1 month suggests that only a few cells can be visualized migrating during the time of a continued time-lapse analysis ( $24 \mathrm{~h}$ at the most, without harming the embryo) at the confocal microscope. This timing is shorter than that used for demonstrating migration of ventral telencephalic cells in mammals (typically 3-5 days). Nevertheless, we were able to record this migration in live zebrafish embryos, thus providing an additional model for the study of interneuron migration in the vertebrate dorsal telencephalon, to complement observations carried out mainly in tissue or embryo cultures. We observed a cell behavior that is remarkably similar to that reported in mouse brain slices or telencephalic hemisphere cultures [Yozu et al., 2005] and that can be summarized as follows: (a) mostly bipolar shape of migrating neurons, and (b) saltatory movement, due to ex- 
tension of the leading process, followed by nuclear translocation and tailing process retraction (online suppl. videos 8-10, www.karger.com/doi/10.1159/000109853, with other reports of neuronal migration, i.e. [Tanaka et al., 2006]). We also observed that the majority of the migrating cells that we imaged headed for the caudal part of the telencephalon, often migrating through the lateral regions, as if these domains were more permissive or provided cues and/or substrates for their migration. It is highly probable that region specificities exist for the origin, route and destination of zebrafish dorsal interneurons as it has been described for mouse cortical interneurons, which have different features and destinations according to their origin from the medial, lateral or caudal ganglionic eminence [Nery et al., 2002; Xu et al., 2004]. However, a definitive map of the different regions of the ventral telencephalon in developing zebrafish is still missing [Mueller et al., 2006], so it may be premature to interpret the behavior of zebrafish migrating interneurons on the basis of their origin.

The visualization of the interneuron migrations in the telencephalon of developing zebrafish opens up the possibility of performing genetic screens to discover new, unexpected players in this migration using forward genetic approaches.

\section{Migration of Cerebellar Neuron Precursors in the}

$\operatorname{tg}(1.4 \mathrm{dlx} 5 \mathrm{a}-6 \mathrm{a})$ and $\operatorname{tg}(\mathrm{Xeom}: \mathrm{GFP})$ Transgenic Lines

Cell migration in the RL of developing zebrafish embryos was the first neuronal migration recorded in a live vertebrate [Koster and Fraser, 2001] and this work opened up a range of possibilities for live imaging in the zebrafish embryo. Although the migrating cells were well characterized in many aspects of their behavior, the final destination and phenotype of the migrating cells was not investigated. The $\mathrm{RL}$ and the adjacent cerebellar ventricular zone are the source of diverse populations of cells, and there are still controversial issues regarding the competence of these 2 proliferative areas to generate the various cerebellar and brainstem lineages. For the cerebellar lineages, the classical view hypothesized a changing competence of the cerebellar ventricular zone to generate DCN neurons, Purkinje cells, Golgi cells and stellate/basket cells in temporal succession [Wang and Zoghbi, 2001], whereas the RL was considered as the source of all granule neurons. More recent genetic map studies [Hoshino et al., 2005; Machold and Fishell, 2005; Wang et al., 2005, reviewed in Wingate, 2005] revealed that the RL also produces DCN neurons and other noncerebellar derivatives, including neurons of the precerebellar nuclei (generating mossy fibers projecting to the cerebellar granules) and cochlear nuclei. A key to solve these controversies is provided by live observation of cell migration in the hindbrain region using zebrafish transgenic lines, where permanent genetic markers allow for the identification of the phenotype of the migrated cells at later times. We noticed that 2 of the transgenic lines that we use for our studies of neuronal migration bear fluorescent cells in this region from early stages to adulthood, thus allowing us to study the migration and differentiation of cell populations in the hindbrain region of the zebrafish. In the $\operatorname{tg}(1.4 d l \times 5 a-$ $6 a: G F P)$ line, GFP+ cells appear in the upper RL at late somitogenesis and can be visualized migrating towards the ventral side up to $48 \mathrm{hpf}$. We believe that these cells are similar to those imaged at slightly later stages [Koster and Fraser, 2001], or to at least part of them, because they exhibit a similar behavior. Indeed also the dlx5a-6a:GFP+ cells appear on the ventricular side of the upper RL and rapidly move towards the mid-hindbrain boundary, which they use as a guide during their ventral migration. However, given the changing in competence of the upper RL observed at different developmental points, it is possible that cells described here acquire a different phenotype than those generated at a later time. The use of a stable transgenic line, instead of a transient genetic marker [as in Koster and Fraser, 2001] allowed us to follow the fate of these cells in developing and adult zebrafish. We therefore established that dlx5a-6a:GFP+ cells migrating along the $\mathrm{RL}$ at this early stage develop into a population of cerebellar neurons in which soma is mainly located in the Purkinje cell layer, dendrites are distributed throughout the molecular layer and axons project out of the cerebellum. Only a few of them express the Purkinje cell marker zebrin II [Lannoo et al., 1991] and GABA-synthesizing enzymes gad65/67a,b, whereas many express calretinin [Castro et al., 2006b]. These features suggest that dlx5a6a:GFP+ cells in the zebrafish cerebellum are eurydendroid neurons, the equivalent in the fish of the neurons of the DCN that project outside of the cerebellum [Ikenaga et al., 2005; Nieuwenhuys, 1988]. Indeed, recent studies in the mouse have shown that glutamatergic neurons of the DCN are generated in the upper RL [Wang et al., 2005], rather than in the cerebellar ventricular zone as hypothesized by classical lineage studies. Similar conclusions were reached by others [Fink et al., 2006], where glutamatergic DCN cells were found to use eomes/tbr2 and tbr1 transcription factors for their differentiation program. The expression of a gene of the $d l x$ family $(d l x 6 a)$ in zebrafish eurydendroid cell precursors may be due to a different genetic program used by cerebellar projection neu- 
rons in fish versus mammals, as predictable on the basis of the overt differences in organization between the 2 cerebellar systems [separate centers for Purkinje cells and DCN in amniotes, intermingled Purkinje cells and projection neurons in fish, Nieuwenhuys et al., 1988]. Further investigation is ongoing to clarify this point.

More surprising is perhaps the observation that the generation of Purkinje cell precursors may be visualized in the $\operatorname{tg}($ Xeom:GFP) transgenic line. Here, the appearance of GFP+ cells in the rostral cerebellar ventricular zone lends support to the view [shared by classical and more novel lineage studies, see Wingate, 2005 for review] that GABAergic Purkinje cells are not the progeny of RL progenitors but are generated in the cerebellar ventricular zone. We are a little more puzzled by the fact that an eomesodermin promoter (though heterologous) is able to drive expression (at low levels) of GFP in Purkinje cells, a GABAergic, inhibitory neuron type. The expression of eomes in the developing mid-hindbrain region of zebrafish has been known for long time, although it was difficult to identify the structures that express it [Mione et al., 2001]. It appears that it is the entire ventricular zone of the cerebellar primordium that expresses eomes during development [see fig. 4 in Mione et al., 2001]. Here too, further studies are needed to clarify the mode of migration of Purkinje cell precursors.

In conclusion, our studies of neuronal migration using zebrafish transgenic lines which stably express fluorescent markers in developing neurons through their life has allowed us to establish the origin, migration mode and route, and final differentiation of mitral cells in the OB, glutamatergic neurons in the septum, interneurons in the dorsal telencephalon, eurydendroid and Purkinje cells in the cerebellum of this genetic model.

\section{Acknowledgments}

We are very grateful to Federica Pezzimenti for expert technical help and to Antonio Renna for taking care of the fish facility. We thank Dario Nicolini for help with video compression, Dr. M. Ekker for the $\operatorname{tg}(1.4 d l x 5 a-6 a: G F P)$ transgenic line, Drs. Yoshida and Mishina for the TBR1 genomic clone, Dr. R. Hawkes for the zebrin II antiserum and Dr. S. Higashijima for the vglut2.1a.b.c, vglut2.2a,b.c and gad65/67a/67b probes. We are grateful to Prof. S. Wilson for hosting the initial stages of this project in his laboratory at University College London. The work for this study at University College London was supported by a project grant to Prof. S. Wilson and M.M. from the Wellcome Trust. Our work is supported by the IFOM-IEO Campus.

\section{References}

Alvarez-Buylla A (1997): Mechanism of migration of olfactory bulb interneurons. Semin Cell Dev Biol 8:207-213.

-Anderson S, Mione M, Yun K, Rubenstein JL (1999): Differential origins of neocortical projection and local circuit neurons: role of Dlx genes in neocortical interneuronogenesis. Cereb Cortex 9:646-654.

-Anderson SA, Eisenstat DD, Shi L, Rubenstein JL (1997): Interneuron migration from basal forebrain to neocortex: dependence on Dlx genes. Science 278:474-476.

-Brox A, Puelles L, Ferreiro B, Medina L (2004): Expression of the genes Emxl, Tbrl, and Eomes (Tbr2) in the telencephalon of Xenopus laevis confirms the existence of a ventral pallial division in all tetrapods. J Comp Neurol 474:562-577.

Brunjes PC, Greer CA (2003): Progress and directions in olfactory development. Neuron 38:371-374.

Bulfone A, Smiga SM, Shimamura K, Peterson A, Puelles L, Rubenstein JL (1995): T-brain-1: a homolog of brachyury whose expression defines molecularly distinct domains within the cerebral cortex. Neuron 15:6378.

\begin{abstract}
Bulfone A, Wang F, Hevner R, Anderson S, Cut- Costagli A, Kapsimali M, Wilson SW, Mione M forth T, Chen S, Meneses J, Pedersen R, Axel R, Rubenstein JL (1998): An olfactory sensory map develops in the absence of normal projection neurons or GABAergic interneurons. Neuron 21:1273-1282.

Byrd CA, Brunjes PC (1995): Organization of the olfactory system in the adult zebrafish: histological, immunohistochemical, and quantitative analysis. J Comp Neurol 358:247-259.

-Castro A, Becerra M, Manso MJ, Anadon R (2006a): Calretinin immunoreactivity in the brain of the zebrafish, Danio rerio: distribution and comparison with some neuropeptides and neurotransmitter-synthesizing enzymes. I. Olfactory organ and forebrain. J Comp Neurol 494:435-459.

-Castro A, Becerra M, Manso MJ, Anadon R (2006b): Calretinin immunoreactivity in the brain of the zebrafish, Danio rerio: distribution and comparison with some neuropeptides and neurotransmitter-synthesizing enzymes. II. Midbrain, hindbrain, and rostral spinal cord. J Comp Neurol 494:792-814.

Cobos I, Puelles L, Martinez S (2001): The avian telencephalic subpallium originates inhibitory neurons that invade tangentially the pallium (dorsal ventricular ridge and cortical areas). Dev Biol 239:30-45.

(2002): Conserved and divergent patterns of Reelin expression in the zebrafish central nervous system. J Comp Neurol 450:73-93.

Denaxa M, Chan CH, Schachner M, Parnavelas JG, Karagogeos D (2001): The adhesion molecule tag-1 mediates the migration of cortical interneurons from the ganglionic eminence along the corticofugal fiber system. Development 128:4635-4644.

- Fink AJ, Englund C, Daza RA, Pham D, Lau C, Nivison M, Kowalczyk T, Hevner RF (2006): Development of the deep cerebellar nuclei: transcription factors and cell migration from the rhombic lip. J Neurosci 26:3066-3076.

-Flames N, Long JE, Garratt AN, Fischer TM, Gassmann M, Birchmeier C, Lai C, Rubenstein JL, Marin O (2004): Short- and longrange attraction of cortical GABAergic interneurons by neuregulin-1. Neuron 44: 251-261.

Fuller CL, Yettaw HK, Byrd CA (2006): Mitral cells in the olfactory bulb of adult zebrafish (Danio rerio): morphology and distribution. J Comp Neurol 499:218-230.

-Gilthorpe JD, Papantoniou EK, Chedotal A, Lumsden A, Wingate RJ (2002): The migration of cerebellar rhombic lip derivatives. Development 129:4719-4728.
\end{abstract}


Gong Q, Shipley MT (1995): Evidence that pioneer olfactory axons regulate telencephalon cell cycle kinetics to induce the formation of the olfactory bulb. Neuron 14:91-101.

-Hamdani EH, Kasumyan A, Doving KB (2001): Is Feeding Behaviour in Crucian Carp Mediated by the Lateral Olfactory Tract? Chem Senses 26:1133-1138.

- Hevner RF, Hodge RD, Daza RA, Englund C (2006): Transcription factors in glutamatergic neurogenesis: conserved programs in neocortex, cerebellum, and adult hippocampus. Neurosci Res 55:223-233.

-Hevner RF, Shi L, Justice N, Hsueh Y, Sheng M, Smiga S, Bulfone A, Goffinet AM, Campagnoni AT, Rubenstein JL (2001): Tbrl regulates differentiation of the preplate and layer 6. Neuron 29:353-366.

Higashijima S, Mandel G, Fetcho JR (2004): Distribution of prospective glutamatergic, glycinergic, and GABAergic neurons in embryonic and larval zebrafish. J Comp Neurol 480:1-18.

-Hoshino M, Nakamura S, Mori K, Kawauchi T, Terao M, Nishimura YV, Fukuda A, Fuse T, Matsuo N, Sone M, Watanabe M, Bito H, Terashima T, Wright CV, Kawaguchi Y, Nakao K, Nabeshima Y (2005): Ptfla, a Bhlh transcriptional gene, defines GABAergic neuronal fates in cerebellum. Neuron 47:201-213.

-Ikenaga T, Yoshida M, Uematsu K (2005): Morphology and immunohistochemistry of efferent neurons of the goldfish corpus cerebelli. J Comp Neurol 487:300-311.

-Kimmel CB, Ballard WW, Kimmel SR, Ullmann B, Schilling TF (1995): Stages of embryonic development of the zebrafish. Dev Dyn 203: 253-310.

Koster RW, Fraser SE (2001): Direct imaging of in vivo neuronal migration in the developing cerebellum. Curr Biol 11:1858-1863.

Koster RW, Fraser SE (2006): Fgf signaling mediates regeneration of the differentiating cerebellum through repatterning of the anterior hindbrain and reinitiation of neuronal migration. J Neurosci 26:7293-7304.

Lannoo MJ, Brochu G, Maler L, Hawkes R (1991): Zebrin II immunoreactivity in the rat and in the weakly electric teleost Eigenmannia (gymnotiformes) reveals three modes of Purkinje cell development. J Comp Neurol 310:215-233.

Letinic K, Rakic P (2001): Telencephalic origin of human thalamic GABAergic neurons. Nat Neurosci 4:931-936.

Machold R, Fishell G (2005): Math1 is expressed in temporally discrete pools of cerebellar rhombic-lip neural progenitors. Neuron 48 : $17-24$.

Manns ID, Mainville L, Jones BE (2001): Evidence for glutamate, in addition to acetylcholine and GABA, neurotransmitter synthesis in basal forebrain neurons projecting to the entorhinal cortex. Neuroscience 107: 249-263.
Manseau F, Danik M, Williams S (2005): A functional glutamatergic neuron network in the medial septum and diagonal band area. J Physiol 566:865-884.

-Marin O, Plump AS, Flames N, Sanchez-Camacho C, Tessier-Lavigne M, Rubenstein JL (2003): Directional guidance of interneuron migration to the cerebral cortex relies on subcortical Slit1/2-independent repulsion and cortical attraction. Development 130: 1889-1901.

Marin O, Rubenstein JL (2001): A long, remarkable journey: tangential migration in the telencephalon. Nat Rev Neurosci 2:780-790.

-Metin C, Baudoin JP, Rakic S, Parnavelas JG (2006): Cell and molecular mechanisms involved in the migration of cortical interneurons. Eur J Neurosci 23:894-900.

- Mione M, Shanmugalingam S, Kimelman D, Griffin K (2001): Overlapping expression of zebrafish T-brain-1 and eomesodermin during forebrain development. Mech Dev 100: 93-97.

Miyashita-Lin EM, Hevner R, Wassarman KM, Martinez S, Rubenstein JL (1999): Early neocortical regionalization in the absence of thalamic innervation. Science 285:906-909.

-Mueller T, Vernier P, Wullimann MF (2006): A phylotypic stage in vertebrate brain development: GABA cell patterns in zebrafish compared with mouse. J Comp Neurol 494:620634.

- Nadarajah B, Alifragis P, Wong RO, Parnavelas JG (2003): Neuronal migration in the developing cerebral cortex: observations based on real-time imaging. Cereb Cortex 13:607-611.

-Nery S, Fishell G, Corbin JG (2002): The caudal ganglionic eminence is a source of distinct cortical and subcortical cell populations. Nat Neurosci 5:1279-1287.

Nieuwenhuys R, Ten Donkelaar HJ, Nicholson C (1988): The Central Nervous System of Vertebrates. Heidelberg, Springer-Verlag.

Nomura T, Osumi N (2004): Misrouting of mitral cell progenitors in the Pax6/small eye rat telencephalon. Development 131:787-796.

- Puelles L, Kuwana E, Puelles E, Bulfone A, Shimamura K, Keleher J, Smiga S, Rubenstein JL (2000): Pallial and subpallial derivatives in the embryonic chick and mouse telencephalon, traced by the expression of the genes Dlx-2, Emx-1, Nkx-2.1, Pax-6, and Tbr-1. J Comp Neurol 424:409-438.

Puelles L, Rubenstein JL (2003): Forebrain gene expression domains and the evolving prosomeric model. Trends Neurosci 26:469-476.

Sanchez-Vives MV, McCormick DA (2000): Cellular and network mechanisms of rhythmic recurrent activity in neocortex. Nat Neurosci 3:1027-1034.

Smith CM, Luskin MB (1998): Cell cycle length of olfactory bulb neuronal progenitors in the rostral migratory stream. Dev Dyn 213:220227.

- Stacey NE, Kyle AL (1983): Effects of olfactory tract lesions on sexual and feeding behavior in the goldfish. Physiol Behav 30:621-628.
Stuhmer T, Puelles L, Ekker M, Rubenstein JL (2002): Expression from a Dlx gene enhancer marks adult mouse cortical GABAergic neurons. Cereb Cortex 12:75-85.

Sur M, Rubenstein JL (2005): Patterning and plasticity of the cerebral cortex. Science 310 . 805-810.

Tamamaki N, Fujimori KE, Takauji R (1997): Origin and route of tangentially migrating neurons in the developing neocortical intermediate zone. J Neurosci 17:8313-8323.

Tanaka DH, Maekawa K, Yanagawa Y, Obata K, Murakami F (2006): Multidirectional and multizonal tangential migration of GABAergic interneurons in the developing cerebral cortex. Development 133:2167-2176.

Tropepe V, Sive HL (2003): Can zebrafish be used as a model to study the neurodevelopmental causes of autism? Genes Brain Behav 2:268281.

Tucker ES, Polleux F, LaMantia AS (2006): Position and time specify the migration of a pioneering population of olfactory bulb interneurons. Dev Biol 297:387-401.

-Wang VY, Rose MF, Zoghbi HY (2005): Math1 expression redefines the rhombic lip derivatives and reveals novel lineages within the brainstem and cerebellum. Neuron 48:3143.

Wang VY, Zoghbi HY (2001): Genetic regulation of cerebellar development. Nat Rev Neurosci 2:484-491.

Westerfield M (1995): The Zebrafish Book. A Guide for the Laboratory Use of Zebrafish (Danio rerio). Eugene, University of Oregon Press.

Wilson SW, Rubenstein JL (2000): Induction and dorsoventral patterning of the telencephalon. Neuron 28:641-651.

Wingate R (2005): Math-Map(Ic)S. Neuron 48: $1-4$.

Wullimann MF, Rupp B, Reichert H (1996): Neuroanatomy of the Zebrafish Brain. A Topological Atlas. Basel, Birkhäuser Verlag.

-Xu Q, Cobos I, De La Cruz E, Rubenstein JL, Anderson SA (2004): Origins of cortical interneuron subtypes. J Neurosci 24:2612-2622.

- Yoshida T, Mishina M (2005): Distinct roles of calcineurin-nuclear factor of activated $\mathrm{T}$ cells and protein kinase A-cAMP response element-binding protein signaling in presynaptic differentiation. J Neurosci 25:30673079.

Yozu M, Tabata H, Nakajima K (2005): The caudal migratory stream: a novel migratory stream of interneurons derived from the caudal ganglionic eminence in the developing mouse forebrain. J Neurosci 25:72687277.

Zerucha T, Stuhmer T, Hatch G, Park BK, Long Q, Yu G, Gambarotta A, Schultz JR, Rubenstein JL, Ekker M (2000): A highly conserved enhancer in the Dlx5/Dlx6 intergenic region is the site of cross-regulatory interactions between Dlx genes in the embryonic forebrain. J Neurosci 20:709-721. 